\title{
Chemistry of $\mathrm{Cu}$ deposition by $\mathrm{Cu}(\mathrm{hfac})(\mathrm{tm} v \mathbf{s})$ monitored by $\mathrm{Li}^{+}$ion attachment mass spectrometry
}

\author{
Toshihiro Fujii ${ }^{\text {a) }}$ \\ Department of Chemistry, Faculty of Sciences and Engineering, Meisei University, Hodokubo 2-1-1, \\ Hino, Tokyo 191-8506, Japan \\ Sundaram Arulmozhiraja \\ Environmental Chemistry Division, National Institute for Environmental Studies, 16-2 Onogawa, \\ Tsukuba, Ibaraki 305-8506, Japan \\ Megumi Nakamura and Yoshiro Shiokawa \\ Canon Anelva Texnix Corporation, Bubai, Fuchu, Tokyo 183-0033, Japan
}

(Received 4 April 2006; accepted 27 June 2006; published online 31 October 2006)

\begin{abstract}
Ion attachment mass spectrometry was used for continuous in situ analysis of coordinated products formed during copper chemical vapor deposition ( $\mathrm{Cu}$ CVD) by $\mathrm{Cu}(1,1,1,5,5,5$-hexafluoroacetylacetonate)(vinyltrimethylsilane) $[\mathrm{Cu}(\mathrm{hfac})(\mathrm{tmvs})]$ in a simple tubular reactor. This study of the thermally labile $\mathrm{Cu}(\mathrm{hfac})(\mathrm{tmvs})$ demonstrated the utility of this method for detecting molecular ions of labile compounds. The results demonstrate the feasibility of monitoring the deposition chemistry of $\mathrm{Cu}(\mathrm{hfac})(\mathrm{tmvs})$ by generating $\mathrm{Li}^{+}$adduct molecular ions by means of the $\mathrm{Li}^{+}$ion attachment technique. The reaction pathways for $\mathrm{Cu} C V D$ by $\mathrm{Cu}(\mathrm{hfac})(\mathrm{tmvs})$ were studied by analysis of the reaction products. $\mathrm{H}(\mathrm{hfac})$ and tmvs were identified as the main products when $\mathrm{Cu}(\mathrm{hfac}) \mathrm{tmvs}$ was heated at temperatures ranging from room temperature to $160{ }^{\circ} \mathrm{C}$ in the reactor. The rate constant for $\mathrm{Cu}$ deposition, $k(1 / \mathrm{s})$, was determined to be $1.6 \times 10^{6} \exp \left(-10.2 \mathrm{kcal} / \mathrm{mol} R_{t}\right)$. (C) 2006 American Institute of Physics. [DOI: 10.1063/1.2360768]
\end{abstract}

\section{INTRODUCTION}

As the electronics industry moves to higher-density integrated circuit (IC) devices, the circuits will have to be fabricated on an increasingly small scale, and the metallic electrical interconnects between the individual components will also need to be miniaturized. For this reason, copper will soon replace aluminum as the conductive interconnect material for ICs because copper has higher conductivity and higher resistance to electromigration than aluminum. ${ }^{1}$ Chemical vapor deposition (CVD) is a superior process ${ }^{2-4}$ for producing these microscopic metal features. CVD of metals such as $\mathrm{Al}$ and $\mathrm{Cu}$, which are suitable for microelectronic applications, has been studied extensively. In this technique, a volatile metal-organic complex in the gas phase is allowed to come into contact with the area of a circuit where the growth of a metal film is required. The precursor molecule for CVD must have a high vapor pressure, low decomposition temperature, and facile decomposition mechanism. Several classes of $\mathrm{Cu}$ metal complexes have been explored as CVD precursors, ${ }^{5}$ and these complexes generally combine copper atoms with a pair of ligands to produce a volatile liquid that can be easily decomposed to free the copper atoms for the formation of the copper film.

Extensive study of $\mathrm{Cu}-\mathrm{CVD}$ processes has led us to a good understanding of the mechanism of copper deposition by metal complexes. ${ }^{6-10}$ Analysis of reaction products is a useful technique for clarifying possible reaction pathways,

\footnotetext{
a) Author to whom correspondence should be addressed; electronic mail: fujji@chem.meisei-u.ac.jp
}

and mass spectrometry has played an important role in product analysis. ${ }^{5,11-13}$ For instance, Naik et al. ${ }^{13}$ analyzed the reaction products of $\mathrm{Cu}(1,1,1,5,5,5$-hexafluoroacetylacetonate)(vinyltrimethylsilane) $[\mathrm{Cu}(\mathrm{hfac})(\mathrm{tmvs})]$, which is one of the CVD precursors. Naik et al. identified the major product as $\mathrm{Cu}(\mathrm{hfac})_{2}$ and proposed that the copper formation proceeded via a reversible disproportionation reaction. Zheng et $a l .{ }^{12}$ studied the gas-phase evolution and decomposition pathways of $\mathrm{Cu}(\mathrm{hfac})_{2}$ with an in situ electron ionization (EI) mass spectrometer and identified the most likely pathways for precursor decomposition. Substantial progress has been made in the interpretation of mass spectra. However, the severe fragmentation that occurs during EI mass spectrometry hampers correct interpretation of the spectra.

We recently showed that compared to traditional EI mass spectrometry, $\mathrm{Li}^{+}$ion attachment mass spectrometry (IAMS) (Refs. 14-19) has considerable advantages for monitoring perfluorocarbons (PFCs). Unlike traditional mass spectrometry, which involves ionization by high-energy electrons, IAMS preserves the structure of PFCs, allowing detection of the compounds as adduct ions without any fragmentation.

In this study, we used a technology based on $\mathrm{Li}^{+}$ion attachment mass spectrometry to monitor the deposition chemistry of $\mathrm{Cu}(\mathrm{hfac})$ (tmvs). Any analytical technique for this reagent must meet the challenges posed by the fact that it is thermally labile, corrosive, and condensable. By means of $\mathrm{Li}^{+}$IAMS, we were able to detect a molecular ion. In this paper, we also discuss the suitability and applicability of the technique for investigating the possible reaction pathways and reaction kinetics of CVD by means of direct, real-time detection of $\mathrm{Cu}(\mathrm{hfac})(\mathrm{tmvs})$ products emitted from a low- 


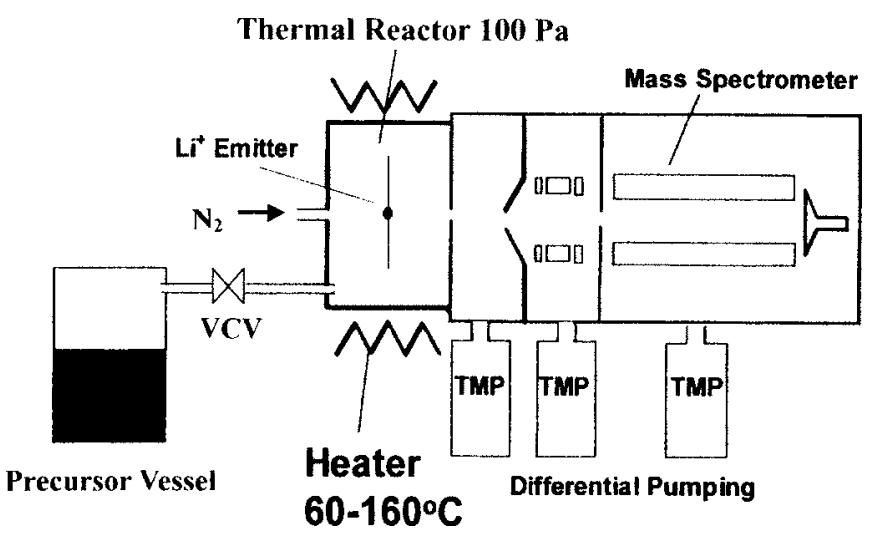

FIG. 1. Schematic of the experimental setup. The system consists of a QMS equipped with a $\mathrm{Li}^{+}$ion attachment reaction chamber. A gaseous stream of the $\mathrm{Cu}(\mathrm{hfac})$ (tmvs) reagent from a sample vessel is directed into the reaction chamber through a variable-conductance valve (VCV). TMP corresponds to turbomolecular pump.

pressure CVD system equipped with a simple thermal reactor. We expect this technique to be useful for optimizing the operation and characteristics of the system.

\section{EXPERIMENT}

\section{Apparatus}

All experiments were performed with a modified version of a specially prepared IAMS apparatus (Anelva Corp.) consisting of a quadrupole mass spectrometer (QMS), a $\mathrm{Li}^{+}$ion emitter, and a thermal reactor (Fig. 1). $\mathrm{Cu}$ (hfac)(tmvs) $(\mathrm{Cu}-$ praSelect blend, Schumacher Inc.) was supplied directly to the sample vessel by means of a variable conductance valve $(\mathrm{VCV})$. The precursor vessel and VCV were maintained at room temperature. A $6 \mu \mathrm{l} / \mathrm{min}$ amount of the precursor was transferred from the vessel to the thermal reactor through a $5 \mathrm{~cm}$ diameter glass tubing, which was maintained at room temperature. The reactor was a tubular, resistively heated hot-wall chamber equipped with $\mathrm{Li}^{+}$ion emitter centered within it. $\mathrm{N}_{2}$ was used as a third-body gas, and the total pressure of the $\mathrm{Cu}$ precursor/ $\mathrm{N}_{2}$ gas mixture was fixed at $100 \mathrm{~Pa}$. The partial pressure of the precursor gas in the reactor was held at $0.1 \mathrm{~Pa}$. The reactor pressure was measured with a Baratron gauge (MKS Instruments). Omega CN-2010 series programmable temperature controllers were used to ensure uniform heating across the reactor, and ironConstantan thermocouples were employed to measure all temperatures with an estimated accuracy of $\pm 2{ }^{\circ} \mathrm{C}$. The reactor was fixed to the main vacuum envelope, which housed the QMS for product analysis. In situ ionization ensured reliable precursor transport from the thermal reactor into the mass analyzing part of the system and accurate analysis of gas-phase reaction species in the thermal reactor.

The apparent activation energies for $\mathrm{Cu}$ deposition were determined from plots of $\mathrm{Cu}(\mathrm{hfac})(\mathrm{tmvs})$ and tmvs for experiments carried out in the temperature range from 60 to 60 to $160{ }^{\circ} \mathrm{C}$.

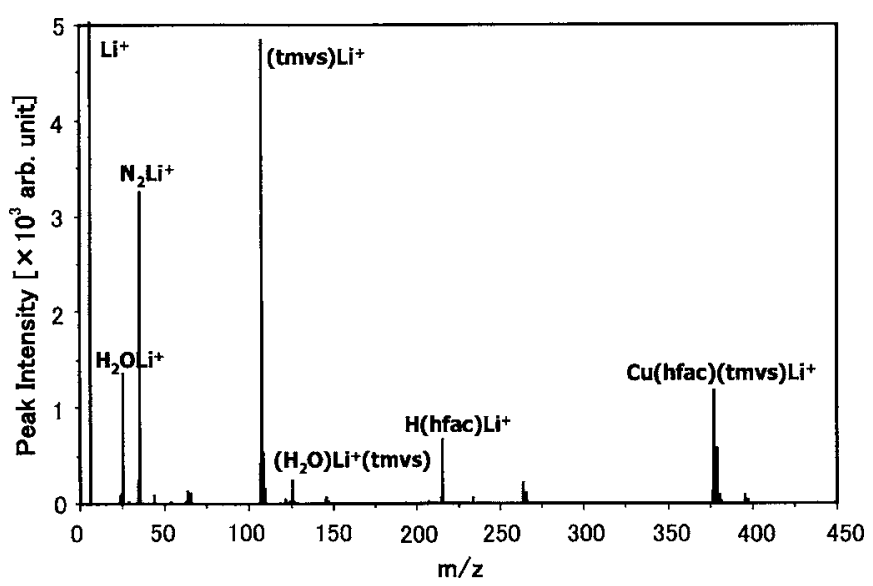

FIG. 2. Mass spectra of the gaseous substances obtained from the simulated $\mathrm{Cu}-\mathrm{CVD}$ reactor at room temperature.

\section{Mass spectrometry procedure}

Mass spectrometric measurements were performed downstream of the thermal reactor system for characterization of the by-products. The QMS was operated in both fullscale and selective-ion monitoring (SIM) modes. The fullscale spectra aided in the qualitative identification of process by-products. The spectrum from 1 to 400 amu was scanned repeatedly during the thermal process. The SIM mode was used to monitor selected ions of interest. The SIM profiles were useful for real-time monitoring of unreacted process gases and process by-products.

\section{RESULTS AND DISCUSSION}

\section{Mass spectrum}

Figure 2 shows a typical $\mathrm{Li}+$ adduct mass spectrum of the as-received $\mathrm{Cu}(\mathrm{hfac})(\mathrm{tmvs})$ in the mass range of up to $m / z=400$. This spectrum was acquired with the precursor vaporizer, QMS inlet lines, and reactor at room temperature, which is low enough to cause $\mathrm{Cu}(\mathrm{hfac})(\mathrm{tmvs})$ complex no premature decomposition. This spectrum includes the background peaks. The $\mathrm{Li}^{+}$adduct molecular ion for $\mathrm{Cu}$ (hfac)(tmvs) was observed at $m / z=387$, without any fragmentation. This spectrum is completely different from the $70 \mathrm{eV}$ EI mass spectrum, which contains many fragment ions, such as (tmvs) ${ }^{+},($tmvs $) \mathrm{Li}^{+}\left(\mathrm{H}_{2} \mathrm{O}\right),(\text { tmvs })_{2}{ }^{+}$, $\mathrm{H}(\mathrm{hfac})^{+} \mathrm{H}(\mathrm{hfac})^{+}\left(\mathrm{H}_{2} \mathrm{O}\right), \quad \mathrm{Cu}(\text { tmvs })_{2}, \quad \mathrm{Cu}(\mathrm{tmvs})(\mathrm{hfac})^{+}$, $\mathrm{Cu}($ tmvs $)(\text { hfac })^{+}\left(\mathrm{H}_{2} \mathrm{O}\right)$, and $\mathrm{CF}$, but no molecular ion.

In addition to the molecular ion, another important feature of the IAMS spectrum (Table I) is the presence of peaks at $m / z=107\left[(\mathrm{tmvs}) \mathrm{Li}^{+}\right] \quad 125 \quad\left[(\mathrm{tmvs}) \mathrm{Li}^{+}\left(\mathrm{H}_{2} \mathrm{O}\right)\right], 207$ $\left[(\text { tmvs })_{2} \mathrm{Li}^{+}\right] 215\left[\mathrm{H}(\mathrm{hfac}) \mathrm{Li}^{+}\right]$, and $233\left[\mathrm{H}(\mathrm{hfac}) \mathrm{Li}^{+}\left(\mathrm{H}_{2} \mathrm{O}\right)\right]$. We attribute these ions not to the fragmentation of $\mathrm{Cu}$ (tmvs)(hfac) $\mathrm{Li}^{+}$but to the presence of traces of the tmvs and $\mathrm{H}(\mathrm{hfac})$ ligands, which are employed in the synthesis of $\mathrm{Cu}^{\mathrm{I}}$ (tmvs)(hfac), in the as-received reagnet. Furthermore, the presence of an unidentified ionic species at $m / e=65,121$, and 145 seems to indicate that the as-received reagent is actually a mixture of compounds, including compounds involved in the synthesis of the reagent. 
TABLE I. Assignments and relative intensities of $\mathrm{Li}^{+}$adduct peaks obtained from thermal reaction of $\mathrm{Cu}(\mathrm{hfac})(\mathrm{tmvs})$ at reactor temperatures of 25 and $130{ }^{\circ} \mathrm{C}$.

\begin{tabular}{|c|c|c|c|}
\hline$m / z$ & $\mathrm{Li}^{+}$adduct & $\begin{array}{l}\text { Relative intensity } \\
\qquad\left(25^{\circ} \mathrm{C}\right)\end{array}$ & $\begin{array}{l}\text { Relative intensity } \\
\qquad\left(130{ }^{\circ} \mathrm{C}\right)\end{array}$ \\
\hline 25 & $\mathrm{H}_{2} \mathrm{Oli}^{+}$ & 43 & 51 \\
\hline 35 & $\mathrm{~N}_{2} \mathrm{Li}^{+}$ & 100 & 100 \\
\hline 43 & $\left(\mathrm{H}_{2} \mathrm{O}\right)_{2} \mathrm{Li}^{+}$ & 3 & 4 \\
\hline 51 & $\mathrm{CO}_{2} \mathrm{Li}^{+}$ & 1 & $\cdots$ \\
\hline 53 & $\mathrm{~N}_{2} \mathrm{Li}^{+}\left(\mathrm{H}_{2} \mathrm{O}\right)$ & 1 & 1 \\
\hline 63 & $\left(\mathrm{~N}_{2}\right)_{2} \mathrm{Li}^{+}$ & 5 & 5 \\
\hline 65 & Not identified & 4 & $\cdots$ \\
\hline 107 & $(\mathrm{tmvs}) \mathrm{Li}^{+}$ & 14 & 16000 \\
\hline 121 & Not identified & 1 & $\cdots$ \\
\hline 125 & $\left(\mathrm{H}_{2} \mathrm{O}\right) \mathrm{Li}^{+}(\mathrm{tmvs})$ & 7 & 2100 \\
\hline 145 & Not identified & 2 & $\cdots$ \\
\hline 207 & $(\mathrm{tmvs})_{2} \mathrm{Li}^{+}$ & 1 & 30 \\
\hline 215 & $\mathrm{H}(\mathrm{hfac}) \mathrm{Li}^{+}$ & 21 & 1200 \\
\hline 233 & $\mathrm{H}(\mathrm{hfac}) \mathrm{Li}^{+}\left(\mathrm{H}_{2} \mathrm{O}\right)$ & 2 & 110 \\
\hline 263 & $\mathrm{Cu}(\mathrm{tmvs})_{2}$ & 6 & 180 \\
\hline 377 & $\mathrm{Cu}(\mathrm{hfac})(\mathrm{tmvs}) \mathrm{Li}^{+}$ & 37 & $\cdots$ \\
\hline 395 & $\mathrm{Cu}(\mathrm{hfac})(\mathrm{tmvs}) \mathrm{Li}^{+}\left(\mathrm{H}_{2} \mathrm{O}\right)$ & 3 & $\cdots$ \\
\hline
\end{tabular}

The background mass spectrum generally showed abundant $\mathrm{H}_{2} \mathrm{OLi}^{+}$as well as other adduct ion with intense peak at $m / z=35,51$, and $63 . \mathrm{H}_{2} \mathrm{OLi}^{+}$is probably derived from the ubiquitous water in the system and the nitrogen carrier gas. Ions at $m / z=35,43,51,53$, and 63 were assigned to $\mathrm{N}_{2} \mathrm{Li}^{+}$, $\left(\mathrm{H}_{2} \mathrm{O}\right)_{2} \mathrm{Li}^{+} \mathrm{CO}_{2} \mathrm{Li}^{+}, \mathrm{N}_{2} \mathrm{Li}^{+}\left(\mathrm{H}_{2} \mathrm{O}\right)$, and $\left(\mathrm{N}_{2}\right)_{2} \mathrm{Li}^{+}$, respectively.

\section{Simulated Cu(hfac)(tmvs) CVD monitoring}

One important objective of this study was to determine the fraction of $\mathrm{Cu}(\mathrm{hfac})(\mathrm{tmvs})$ converted to reactive byproducts and other species during thermal CVD processes. Figure 2 shows the major by-products at a reactor temperature $\left(R_{t}\right)$ of $25{ }^{\circ} \mathrm{C}$. Peaks with relative intensities of at least $3 \%$ are shown. The mass spectrum of the gaseous products was complex, with $m / e=107\left[(\mathrm{tmvs}) \mathrm{Li}^{+}\right]$being the most intense peak. Another interesting peak, at $\mathrm{m} / \mathrm{e}$ $=215\left[\mathrm{H}(\mathrm{hfac}) \mathrm{Li}^{+}\right]$was found to be characteristic of $\mathrm{H}(\mathrm{hfac})$ and $\mathrm{CF}_{3} \mathrm{COCH}_{2} \mathrm{COCF}_{3}$, as indicated by the mass number. This observation is consistent with the prevailing decomposition mechanism, by which the cleavage of the $\mathrm{Cu}-$ tmvs bond produces tmvs radicals and $\mathrm{Cu}(\mathrm{hfac})$ subsequently abstracts hydrogen atoms from the surface-bound hydroxyl groups on the surrounding glass chamber, resulting in the production of $\mathrm{H}(\mathrm{hfac})$.

Other large peaks were identified as $\mathrm{H}_{2} \mathrm{OLi}^{+}($tmvs $)$ $(m / z=125), \mathrm{Li}^{+}(\text {tmvs })_{2} \quad(m / z=207) \quad \mathrm{H}($ hfac $) \mathrm{Li}^{+} \mathrm{H}_{2} \mathrm{O} \quad(m / z$ $=233)$, and $\mathrm{Cu}(\mathrm{hfac})(\mathrm{tmvs}) \mathrm{Li}^{+} \mathrm{H}_{2} \mathrm{O}(\mathrm{m} / \mathrm{z}=395)$. These species can be associated ions, because the concentrations of tmvs and $\mathrm{H}_{2} \mathrm{O}$ are high. The advantage of the present method lies in the generation of ions that do not fragment and can thus be easily identified. However, because the identifications are based only on the mass number, they are not unambiguous.

The data in Table I show a significant difference in product distributions for the two temperatures. (The mass spec-

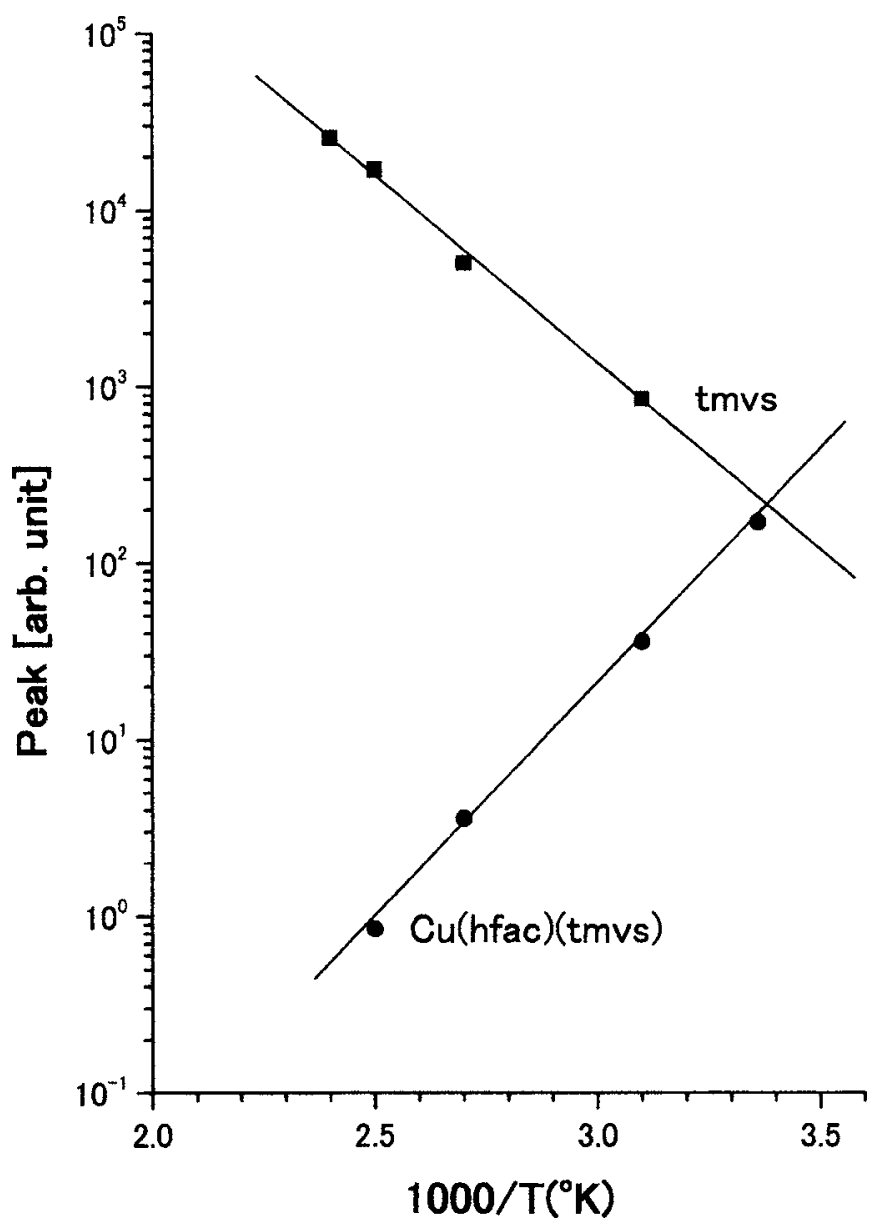

FIG. 3. A plot for the $\mathrm{Cu}(\mathrm{hfac})($ tmvs $)$ and tmvs signals in the temperature range from 60 to $160{ }^{\circ} \mathrm{C}$.

trum signals were normalized to an arbitrary yield of 100 for $m / e=35$ because their abundances seemed to show some differences.) As expected, the relative intensity of the $\mathrm{Cu}(\mathrm{h}$ fac)(tmvs) peak was lower, while $\mathrm{H}(\mathrm{hfac})$ and tmvs were present abundantly at higher $R_{t}$.

\section{Copper deposition}

We investigated the intensities of the $\mathrm{Cu}$ (hfac)(tmvs) $\mathrm{Li}^{+}$and (tmvs) $\mathrm{Li}^{+}$signal at $\mathrm{m} / z=377$ and 107 over the temperature range of $60-160{ }^{\circ} \mathrm{C}$ to obtain the rate constant for $\mathrm{Cu}$ deposition on the assumption that (i) an equilibrium situation is established between chemical reaction to deposition and the detection by lithium ion attachment mass spectrometry and that a (ii) simple correlation exists between the adduct ion signal, the product $[\mathrm{Cu}(\mathrm{hfac})(\mathrm{t}-$ mvs) and (tmvs)] concentrations, and $\mathrm{Cu}$ deposition. The slopes of the plots of temperature versus signal intensity in this limited temperature region were constant (Fig. 3). Apparent activation energies $\left(E_{a}\right)$ of 10.2 and $12.2 \mathrm{kcal} / \mathrm{mol}$ for $\mathrm{Cu}$ deposition were calculated from the plots of $\mathrm{Cu}(\mathrm{hfac})(\mathrm{t}-$ mvs) and tmvs, respectively. These values are roughly the same as the activation energies on the order of $12 \mathrm{kcal} / \mathrm{mol}$, determined by Dubois and Zegarski. ${ }^{20}$ It should be noted, however, that the discrepancy between our extracted values and the value of Dubois and Zegarski might be better explained by considering the present assumption. 


\section{Reaction scheme}

It is generally accepted that $\mathrm{Cu}$ deposition with $\mathrm{Cu}(\mathrm{h}$ fac)(tmvs) occurs via the disproportionation reaction ${ }^{5,6}$

$$
\begin{aligned}
& 2 \mathrm{Cu}(\mathrm{hfac})(\text { tmvs }) \rightarrow 2 \mathrm{Cu}(\text { hfac })+2(\text { tmvs }), \\
& 2 \mathrm{Cu}(\mathrm{hfac}) \rightarrow \mathrm{Cu} \downarrow+\mathrm{Cu}(\text { hfac })_{2} .
\end{aligned}
$$

The preliminary kinetic study of $\mathrm{Cu} C V D$ by $\mathrm{Cu}$ (hfac)(tmvs) confirmed that $\mathrm{Cu}$ (hfac)(tmvs) was primarily decomposed to produce tmvs, and the activation energy for $\mathrm{Cu}$ deposition was on the order of $12 \mathrm{kcal} / \mathrm{mol}^{20}$

Our mass spectrometric studies of $\mathrm{Cu}(\mathrm{hfac})$ (tmvs) in the thermal reactor indicated that tmvs and $\mathrm{H}(\mathrm{hfac})$ were the main reaction products. Neither $\mathrm{Cu}(\mathrm{hfac})$ nor $\mathrm{Cu}(\mathrm{hfac})_{2}$ was observed. These findings are not consistent with a mechanism involving the disproportionation reaction [Eqs. (1) and (2)], which has been well documented by many scientists. Our results suggest the following decomposition reaction instead:

$$
\mathrm{Cu}(\mathrm{hfac})+\mathrm{H} \rightarrow \mathrm{Cu} \downarrow+\mathrm{H}(\mathrm{hfac}) .
$$

Farkas et $a l^{21}$ suggested that $\mathrm{Cu}(\mathrm{hfac})$ radicals react with hydrogen atoms from hydroxyl groups bound to the surface of the surrounding chamber to produce $\mathrm{H}(\mathrm{hfac})$ species: our observation of the intense $\mathrm{H}(\mathrm{hfac})$ peak supports the Farkas mechanism.

Density functional theoretical calculations indicate ${ }^{22}$ that the energy of the $\mathrm{Cu}$-tmvs bond is approximately $30 \mathrm{kcal} / \mathrm{mol}$. However, the experimental apparent activation energy of the deposition reaction obtained in this study is much lower than $30 \mathrm{kcal} / \mathrm{mol}$. The hypothesis involving surface reaction of the $\mathrm{Cu}(\mathrm{hfac})$ (tmvs) was somewhat supported by the comparison of the $E_{a}$ value with the calculated $\mathrm{Cu}-$ tmvs bond energy of $30 \mathrm{kcal} / \mathrm{mol}$. Therefore, it is reasonable to speculate that the $\mathrm{Cu}$-tmvs bond is cleaved by means of a heterogeneous reaction involving the reactor surface. We suggest that the reaction to break the $\mathrm{Cu}$-tmvs bond is catalytic.

\section{CONCLUDING REMARKS}

We employed IAMS to monitor $\mathrm{Cu}$ CVD by $\mathrm{Cu}$ (hfac)(tmvs). A uniquely designed QMS system along with a $\mathrm{Li}^{+}$ion attachment technique and a laboratory-built direct introduction system provided molecular ion such as $\mathrm{Cu}$ (hfac)(tmvs) $\mathrm{Li}^{+}$which could be used to estimate volume balances for $\mathrm{Cu}-\mathrm{CVD}$ reagent used during processing. We believe that this kinetic information will be useful for improving the growth rate uniformity of CVD processes.

\section{ACKNOWLEDGMENTS}

This work was supported in part by The New Energy and Industrial Technology Development Organization (NEDO) under a fund for Fundamental Technology Research Facilitation Program.

${ }^{1}$ L. Jian, H. Stella, S. Russell, and J. W. Mayer, in Crucial Issues in Semiconductor Materials and Processing Technologies edited by S. Coffa, F. Priolo, E. Rimini, and J. M. Poate NATO Advanced Studies Institute, Series E: Applied Sciences, Vol. 222, (Kluwer, Dordrecht, 1992), p. 305.

${ }^{2}$ C. K. Hu and J. M. Harper, Mater. Chem. Phys. 52, 5 (1998).

${ }^{3}$ D. Kim, R. H. Wentorf, and W. N. Gill, J. Electrochem. Soc. 140, 3273 (1993).

${ }^{4}$ S. K. Lakshmanan and W. N. Gill, Thin Solid Films 338, 24 (1999)

${ }^{5}$ V. M. Donnelly and M. E. Gross, J. Vac. Sci. Technol. A 11, 66 (1993).

${ }^{6}$ S. L. Cohen, M. Liehr, and S. Kasi, Appl. Phys. Lett. 60, 1585 (1992).

${ }^{7}$ P. J. Lin and M. C. Chen, Jpn. J. Appl. Phys., Part 1 38, 4863 (1999).

${ }^{8}$ S. K. Reynolds, C. J. Smart, and E. F. Baran, Appl. Phys. Lett. 59, 2332 (1991).

${ }^{9}$ Y. K. Chae, Y. Shimogaki, and H. Komiyama, J. Electrochem. Soc. 145, 4226 (1998).

${ }^{10}$ D. Kim, R. H. Wentorf, and W. N. Gill, J. Electrochem. Soc. 140, 3267 (1993).

${ }^{11}$ K. C. Lin, C. Marcadal, S. Gauguile, B. Zheng, J. Schmitt, and L. Chen, Proceedings of the Advanced Semiconductor Manufacturing Conference, 1999, p. 440.

${ }^{12}$ B. Zheng et al., Mater. Chem. Phys. 41, 173 (1995).

${ }^{13}$ M. B. Naik, W. N. Gill, R. H. Wentorf, and R. R. Reeves, Thin Solid Films 262, 60 (1995).

${ }^{14}$ T. Fujii M. Ogura, and H. Jimba, Anal. Chem. 61, 1026 (1989).

${ }^{15}$ T. Fujii and K. Syouji, Phys. Rev. A 46, 3555 (1992).

${ }^{16}$ T. Fujii, Mass Spectrom. Rev. 19, $111(2000)$.

${ }^{17}$ T. Fujii and M. Kareev, J. Appl. Phys. 89, 2543 (2001).

${ }^{18}$ M. Nakamura, K. Hino, T. Sasaki, Y. Shiokawa, T. Fujii, M. Takayanagi, and M. Nakata, J. Vac. Sci. Technol. A 22, 2347 (2004).

${ }^{19}$ T. Fujii, S. Arulmozhiraja, M. Nakamura, and Y. Shiokawa, Anal. Chem. 73, 2937 (2001).

${ }^{20}$ L. H. Dubois and B. R. Zegarski, J. Electrochem. Soc. 139, 3295 (1992).

${ }^{21}$ J. Farkas, M. J. Hampden-Smith, and T. T. Kodas, J. Electrochem. Soc. 141, 3539 (1994).

${ }^{22}$ S. Arulmozhiraja and T. Fujii, Mol. Phys. 103, 3293 (2005). 